Logic and Logical Philosophy

Volume 15 (2006), 155-162

DOI: $10.12775 /$ LLP.2006.009

\title{
Anna Pietryga
}

\section{TWO KINDS OF UNEXPECTED PROBLEMS IN WRITINGS ON LOGIC}

\footnotetext{
Abstract. In some texts concerning logic the reader faces unexpected problems, namely: 1) incongruities between the commentary and logical solutions offered and 2) mistakes concerning external facts.
}

There are some problems, unexpected ones, the reader may encounter in some of the texts written on various logics. These are internal incongruities between the logical commentary and solutions offered as well as mistakes concerning external facts (these two may be called internal and external falsehoods, respectively). Incidentally, all examples given below concern the work of paraconsistent logicians. This is not to say these logics are the only texts in the world that contain such problems or that every text on paraconsistent logic must contain them.

\section{I}

In some paraconsistent logics problems occur not merely as a feature of the material which is being processed and may prove dangerous for the logical machinery (as it is the case e.g. in Newton Da Costa's $C_{n}[2]$ ); this time they appear within the machinery itself. What I mean are incongruities between declarations and the practice the reader may notice. They make author's comments misleading for the reader. Two examples of this kind in paraconsistent logics come from Rescher and Brandom [10] and Hunter [6]. In both these works, the reader is informed that a formula and its negation are no longer linked to each other and later he or she learns that the link 
needs to become reestablished. Surprisingly, it is no problem for the authors to decide which two formulas should be linked as a formula and its negation, despite the declared decoupling. Thus, the problem encountered by the reader is that the presented theory and the practice he or she observes in the functioning of the logic (the practical solutions the authors present) are in a marked contrast.

Rescher and Brandom declare they are interested in ontological inconsistency, not in epistemological one. They introduce, apart from the "epistemological" possibility of asserting $p$ and asserting $\sim p$ by various "assertors", also a so-called ontological status of a proposition, which is meant to represent a depersonalized opinion of an inconsistent system S (cf. [10], p.138). Ontological status of a proposition $P$ in a given world $w$ is positive (written $\left.[P]_{w}=+\right)$ or negative $\left([P]_{w}=-\right)$. It is meant to specify the actual (ontological) situation as opposed to the epistemological matter of personal beliefs. It is not explained, though, who and how should decide what the "ontological facts" are.

Because the authors are prepared to accept the appearance of actual contradictions, the ontological status of $\mathrm{P}$ and of $\sim \mathrm{P}$ is mutually independent, just as the logical values of any two different simple sentences in classical logic:

\begin{tabular}{|c|c|}
\hline$[P]_{w}$ & {$[\neg P]_{w}$} \\
\hline+ & + \\
\hline+ & - \\
\hline- & + \\
\hline- & - \\
\hline
\end{tabular}

However, even if both a sentence and its negation are assigned the positive ontological status, we are expressly prohibited to assign the same to their conjunction because the authors' standpoint is that "two mutually inconsistent states of affairs might well both be realized in a non-standard world, whereas a single self inconsistent state of affairs can never be realized. Contradictions can be realized distributively but not collectively: self-contradiction must be excluded. We shall always have $[P \wedge \neg P]_{w}=-$ " ([10] p. 7.)

Leaving alone the questions of what a state of affairs is (cf. [13] p. 233), of how to understand distributive or collective realization of contradictions and whether or not the above prohibition is well-justified, we may just notice 
that the decoupling of a formula and its negation did not allow the authors to treat the conjunction of contradictories just like any other conjunction. They take a dogmatic position prohibiting a positive ontological status assignment in this case, disregarding their initial declaration: "It is necessary to insist at the very outset that one should avoid speaking of inconsistent worlds as impossible worlds. This would be question-begging, for it is a prime aim of the present analysis to show that they can be considered as genuinely possible cases. It is the manifestation of a prejudice $(\ldots)$ to hold that inconsistent worlds are ipso facto impossible" [10] p. 4.

Hunter, just like Rescher and Brandom, announces decoupling a formula and its negation, and just like Rescher and Brandom, restores the link between the two sentences when he chooses to. His logic is meant as a logic of beliefs: one may have reasons both to accept a viewpoint and to reject it. The models of his logic consist of objects understood as such reasons ("[T]he definition of a model incorporates no notion of truth and falsity" [6] ch. 3), written, for a given belief $\alpha$, and a set of objects $X$, as:

$+\alpha \in X$, for an argument supporting $\alpha$, and

$-\alpha \in X$, for an argument against $\alpha$.

Hunter's quasi-classical logic is very simple and it does not allow one object to work as an argument for $\alpha$ and against $\beta$. Nevertheless, there is one exception, to be noticed in the following definition:

$+\alpha \in X$ means $X$ contains an argument for the belief $\alpha$ and against the belief $\neg \alpha$.

Similarly, the expression

$-\alpha \in X$ means $X$ contains an argument for the belief $\neg \alpha$ and against the belief $\alpha$.

Hunter introduces a satisfiability relation $\models_{S}$ called strong satisfaction. For this, he has previously (ch. 2) defined what he calls a complementation operation $\sim$, defined half-informally as follows:

$$
\begin{aligned}
& \sim \alpha \text { is } \neg \alpha \\
& \sim(\neg \alpha) \text { is } \alpha
\end{aligned}
$$

The definition is supplemented with a following short informal comment: "The complementation operation is not in the object language. We use it to make clearer definitions for the semantics of Q[uasi] C[lassical] logic". 
There is hardly any other commentary to be found in [6] apart from these two sentences placed in a chapter meant to introduce "some basic definitions".

The definition of strong satisfaction consists of three parts:

$$
\begin{aligned}
& X \models_{\mathrm{S}} \alpha \text { if }+\alpha \in X \\
& X \models_{\mathrm{S}} \neg \alpha \text { if }-\alpha \in X \\
& X \models_{\mathrm{S}} \alpha_{1} \vee \cdots \vee \alpha_{n} \text { iff }\left[X \models_{\mathrm{S}} \alpha_{1} \text { or } \ldots \text { or } X \models_{\mathrm{S}} \alpha_{n}\right] \text { and } \\
& \forall i \text { such that } 1 \leq i \leq n\left[X \models _ { \mathrm { S } } \sim \alpha _ { i } \text { implies } X \models _ { \mathrm { S } } \text { Focus } \left(\alpha_{1} \vee\right.\right. \\
& \left.\left.\cdots \vee \alpha_{n}, \alpha_{i}\right)\right], \text { where Focus is a narrowing of the alternative by the } \\
& \text { indicated item, } \alpha_{i} \text { in this case (cf. [6] ch. } 3 \text { ). }
\end{aligned}
$$

Thus, in the third part of the definition, the strongly implied alternative has to remain satisfied when it gets narrowed by the item whose complement is being strongly satisfied. Therefore a formula and its negation can never both be strongly satisfied by a given set of objects. The link between a formula and its negation - or, between a formula and its complement (Hunter uses both expressions interchangeably in the context) - becomes visible indeed: the point is that actually it has never been destroyed, as can be seen in the definitions of what " $+\alpha$ " refers to, and of what it means for a (complex) formula to be strongly satisfied. Again, as could be seen before in the work by Rescher and Brandom, surprising exceptions are being made just for the pair of formulas consisting of a sentence and its negation. In both cases, the declarations of the authors are challenged by their own decisions.

\section{II}

The second group of problems to be encountered in paraconsistent logics are mistakes in the logical commentary concerning external facts (i.e. facts not concerning the logic being presented). Examples here come from Priest [8] and [9], as well as from da Costa and Krause [3].

Priest mentions Alfred Tarski and his work on liar's paradox and states he is using Tarski's results in his logic. It is perhaps worth noticing that it is hardly true. I have in mind the facts from the history of logic he mentions both in [8] and [9]. Priest states that semantics of English must be internally inconsistent, as English is a semantically closed language in Tarskian sense. This means, according to Priest ([8] p. 118) that English "can adequately express its own semantic concepts" (cf. also Priest [9] p. 14). The problem is that a) Tarski gave more than one condition for semantic closure to occur, 
and b) he states explicitly that natural languages, like Polish or English, are NOT semantically closed. The reasons are as follows.

a) Tarski states explicitly that a given language is semantically closed if:

1. it contains, along with its expressions, also their names and semantic terms concerning these expressions, in particular the term TRUE, and

2. rules of correct usage of the latter term, i.e. TRUE, formulated in the very language in question ([11] pp. 30-31 and [13] pp. 242243).

b) In other works ([12] p. 176 and [14] p. 313) Tarski explains when a language can allow to formulate precise definitions related to the term TRUE: its full lexicon has to be known as well as its purely formal syntactical rules allowing to recognize which of its expressions are sentences.

As concerns everyday language, Tarski leaves no doubt about his opinion: in everyday language (today we speak of "natural" or "ethnic languages") we do not have any definite list of words that can be added to its lexicon, nor a structural definition of a sentence in it. Not knowing which expressions are sentences we must admit that a formal definition of a true sentence is beyond our reach ([11] p. 29, [13] p. 244) (the structural definitions are obviously not meant to give a criterion for deciding about the truth or falsity of particular sentences - cf. [14] p. 317). Thus, according to Tarski, Polish, like English, French etc. is NOT a semantically closed language.

In [8] and [9], Priest does not share Tarski's view. He actually seems not to realise the difference of opinion. (Priest mentions editions of both [11] and [13].) He believes the gap between formal and natural languages has been closed so that "the idea of English as a formal language does not seem at all utopian" ([8], p. 117). This sentence recalls the title of Richard Montague's paper "English as a formal language" [7], where Montague gave reasons why he considered it possible to define a true sentence of English ([7], pp. 208 and 210): he presented a formal language to function as a fragment of English, sketched for it a semantics and a definition of a true formula "in the manner suggested in Tarski [11] for mathematical languages", and expressed confidence as to the possibility of extending the project. Montague does not mention Tarski's doubts, either. It is worth noticing that - to take the simplest example - the lexicon of Montague sample of English is defined to consist of all English proper nouns together with individual variables. Tarski 
could say it was impossible to precisely define that set: the English proper nouns of 1970 need not - actually, cannot - be those of 1933 nor those of 2005 (cf. [11] p. 29)

It is also many a linguist that would like to make linguistic knowledge explicit; unfortunately, the efforts of linguists like Noam Chomsky to find an algorithm allowing to separate correct sentences from incorrect ones and to study the structures of the former were perhaps the most successful in showing how difficult the task is - despite the fact that language is even accessible to children. In each case the simplicity of the task turns out to be illusory. The simplest question: "What is a sentence?" remains a puzzle. Therefore, I think there is no possibility to really disagree with Tarski on natural language.

Besides, even if the grammatical form of a correct declarative sentence were easy to establish, there is no guarantee that there exists a truth value corresponding to each of them. Leaving alone the problem of future events, determinism and indeterminism, one can say there do exist expressions formed like declarative sentences which in some circumstances can be recognized as effective rather than true (cf. [1]), like e.g.:

I swear to tell the truth.

when uttered in court by a witness, or

I christen this ship the John Austin.

when uttered by the queen in a ceremony.

Both of these will have no binding effect if uttered by playing children or by an actor in a theatre performance; this, however, will not make them false. The sentences in question may be supposed to have no truth value despite their grammatical form.

Obviously, even if the truth-value does exist, we may have problems establishing it, like e.g. for sentences:

Euclid had a younger brother who hated geometry, or I thought the credit card was mine.

This, however, is not a problem to be dealt with in a general definition of a true sentence, as has been justly noticed by Tarski (cf. [14], pp. 317-318).

Another example of the second kind of problems is to be noticed in "the logic of complementarity" by Newton da Costa and Décio Krause [3]. The mistake we encounter in their paper concerns the hidden premises we keep using in logical reasoning without being aware of it. 
The term "complementarity" was introduced by Niels Bohr in 1927. To pin down its meaning, Da Costa and Krause assume, after Max Jammer, that it is possible to form a complementarity interpretation of a theory $T$ if:

- $T$ contains (at least) 2 descriptions: $\mathrm{D}_{1}$ and $\mathrm{D}_{2}$ of its substancematter;

- $\mathrm{D}_{1}$ and $\mathrm{D}_{2}$ refer to the same universe of discourse;

- neither $\mathrm{D}_{1}$ nor $\mathrm{D}_{2}$ alone makes it possible to describe satisfactorily every phenomenon we need to describe;

- $\mathrm{D}_{1}$ and $\mathrm{D}_{2}$ are mutually exclusive in the sense that their combination into a single description would lead to logical contradictions

The idea of complementarity aroused serious discussions. As suggested by Feynman (cf. [4] p. 137), the difficulties in understanding it are caused by the fact that we are used to speak about objects whose magnitude and vicinity allows us to handle them in everyday life. In these objects, one of the complementarity descriptions is negligible (cf. [5], p. 91). A change of subject that quantum physics requires does indeed make it difficult for us to adjust. This holds true also for logicians.

Da Costa and Krause state contradiction mentioned in the last complementarity condition appears "if classical logic is applied" (cf. [3], p. 13). This is a mistake. Classical logic by itself would not derive contradiction from complementary descriptions, like e.g. wave/particle descriptions of light, because it does not share our superstitions. Classical logic does not "know" why a particle must not be a wave (and, actually, neither do we). Of course, we can provide it with some extra rules that would render the described result, but this would make us consider a completely different case, not the one da Costa and Krause originally intended to present.

\section{References}

[1] Austin, J. L., How to do things with words, Oxford University Press, 1962.

[2] da Costa, N. C. A., "On the theory of inconsistent formal systems", Notre Dame Journal of Formal Logic vol. XV, no. 4, (1974), 497-510.

[3] da Costa, N.C.A., and D. Krause, The logic of complementarity, PréPublicações do Departamento de Filosofia Universidade Federal de Santa Catarina, year VIII, no. 63, August 2003. http://www.cfh.ufsc.br/ dkrause/pr epub.html

[4] Feynman, R. P., Charakter praw fizycznych, Prószyński i S-ka, Warszawa, 2000. 
[5] Gribbin, J., W poszukiwaniu kota Schroedingera, Zysk i S-ka, Poznań, 1997.

[6] Hunter, A., "Reasoning with contradictory information using quasi-classical logic", Journal of Logic and Computation 10, no. 5, (2000), 677-703. http:// www.cs.ucl.ac.uk/staff/A.Hunter/papers.html

[7] Montague, R., "English as a formal language", in: R. H. Thomason, (ed.), Formal philosophy. Selected papers of Richard Montague, Yale University Press, London, 1979, pp. 188-221.

[8] Priest, G., "Semantic closure", Studia Logica 43, no. 1-2, (1984), 117-129.

[9] Priest, G., In Contradiction, Martinus Nijhoff Publishers, Dordrecht, 1987.

[10] Rescher, N., and R. Brandom, The Logic of Inconsistency. A Study in NonStandard Possible-World Semantics and Ontology, Basil Blackwell, Oxford, 1980.

[11] Tarski, A., Pojęcie prawdy w jezykach nauk dedukcyjnych (The concept of truth in formalized languages), A. Tarski, Pisma logiczno-filozoficzne. Tom 1: Prawda, Wydawnictwo Naukowe PWN, Warszawa, 1933/1995a, pp. 13-172.

[12] Tarski, A., O ugruntowaniu naukowej semantyki (The establishment of scientific seantics), ibid., 1936/1995b, pp. 173-185.

[13] Tarski, A., Semantyczna koncepcja prawdy i podstawy semantyki (The semantic conception of truth and the foundations of semantics), ibid., 1944/1995c, pp. 228-282.

[14] Tarski, A., Prawda i dowód (Truth and Proof), ibid., 1969/1995d, pp. 292-332.

Anna Pietryga

Instytut Filologii Polskiej

Uniwersytet Opolski

Opole, Poland

Anna.Pietryga@uni.opole.pl 